\title{
Vision, Challenge and Path: the "Going Global Strategy" of Chinese Language and Culture from the Perspective of Cultural Confidence
}

\author{
Qijun Guo \\ College of Chinese Language and Culture \\ Jinan University \\ Guangzhou, China 510610
}

\begin{abstract}
In the face of the predicament that the western discourse system still dominates the world and the promotion experience of Chinese language and culture is insufficient, this paper points out that the "Going Global Strategy" of Chinese language and culture is the historical necessity and realistic choice for realizing cultural self-confidence in the context of the new era. It is necessary to make Chinese language an international or regional common language, to promote cultural exchanges as well as the mutual understanding of civilizations, and to build a community with shared future for humanity. Besides, it is vital to dig deep into the excellent tradition and the contemporary values of Chinese culture, to cultivate the communication subject, and to change the communication modes and strategies, thus promoting cultural communication through language communication, gradually enhancing China's rights to speak on the international stage, and enhancing the country's soft power.
\end{abstract}

Keywords-cultural confidence; Chinese language and culture; “Going Global Strategy"; path selection

\section{INTRODUCTION}

China has a long history. And the external exchange of Chinese language has been carried out since ancient China. The strength of national power and the prosperity of Chinese culture were closely related to external exchanges in Chinese history. From the ancient Silk Road in Han Dynasty to the Maritime Silk Road in Ming Dynasty, Chinese cultures of material, system, ideology, and Chinese Character have been spread to the East Asia and the European continent. Cultural exchanges in different periods not only have expanded the influence of Chinese language and culture in the world, but also enhanced the appeal of Chinese language and culture, and promoted the construction of China's national image. Since the ancient times, China has enjoyed the reputation of "a state of etiquette", "an ancient civilized country" and "an Oriental paradise".

Since the 21st century, the world cultural pattern has been developing in a diversified way. However, Western values still dominate the mainstream and cultural misunderstandings and conflicts between Chinese and Western values and cultural concepts still exist. As the most popular and powerful language in the world, English has not changed its status fundamentally. Chinese language as well as Chinese culture is not well known and influential in the world, and their discourse power is not high in the international community. The spread of Chinese language and culture is misinterpreted as "cultural threat" and "cultural invasion". In the pluralistic world cultural pattern, the shaping of self-image is as important as the reconstruction of his image. On the one hand, we should be highly conscious of our own language and culture, so as to achieve "beauty" and cultural self-confidence. On the other hand, we should actively "go out" to promote our own language and culture in order to eliminate misunderstandings, to promote identity, and to re-shape our self-image. Only when other cultural subjects have a high sense of identity with Chinese language and culture can they reduce their cultural misunderstanding, restrain the negative influence of "China threat theory" and "cultural threat theory", and promote the international community to have a real, comprehensive and three-dimensional understanding of China. And that helps us shape China's good international image and improve the soft power of national culture. So, the "going global" of Chinese language and culture is the historical necessity and realistic choice to realize cultural self-confidence.

\section{The Strategic Vision OF "GoING GLOBAL" OF Chinese LANGuAge AND CUlture IN THE NEW ERA}

Since the 18th National Congress, General Secretary Xi Jinping has repeatedly put forward the idea of cultural selfconfidence, building a socialist cultural power and promoting the prosperity and development of Chinese culture. "Cultural self-confidence is a more fundamental, broader and deeper self-confidence. The excellent traditional Chinese culture has bred in the development of civilization for more than 5000 years, while the revolutionary culture and the advanced socialist culture bred in the great struggle between the Party and the people. All these have accumulated the deepest spiritual pursuit of the Chinese nation and represent the unique spiritual symbol of the Chinese nation (Xi Jinping, 2017). Strengthening cultural self-confidence is of great historical and practical significance in the socialist modernization drive. It is "a major issue concerning the rise 
and fall of the national movement, cultural security and the independence of the national spirit." It is related to the realization of the "Chinese dream" and the realization of the "Two Centenary Goals". We should actively promote Chinese culture to the world, participate in the dialogue of world civilizations, promote the mutual use of cultures, enhance the appeal and influence of Chinese culture in the world, and jointly safeguard cultural diversity. In the new era, Chinese language and culture should "go out" with a grand vision of building Chinese language as the universal language of the world or region, promoting cultural exchanges, learning from each other and building a community of shared future for mankind.

\section{A. Language Interchanges: Chinese Language Becomes an International or Regional Common Language}

Common language is an interlanguage used by different native speakers or different monolinguals. Common language can be divided into national common language, regional common language, cross-regional common language and international common language (Zhang Zhiguo, 2016). Language interaction is the basis for dialogue among civilizations. Only by exchanging languages can we promote civilized exchanges better and transcend the gap between civilizations. "Language is an important tool for communication, and it is the key to a country's culture. (Xi Jinping, 2017)"

In order to help Chinese language and culture "go out", we should make Chinese language become an international or regional common language and enhance its reputation in the international community. First, we must pay attention to the status planning of Chinese language, enhance the status of Chinese language in the international areas, expand the use of Chinese language in the international scope, break through the dilemma of "not used in other countries and international occasions", and build a new pattern of Chinese language "going global". In doing so, we gradually promote Chinese language to become an international or regional common language with a high degree of accessibility and a wide range of use in the international community. Second, we should pay attention to the reputation planning of Chinese language. We can fully draw lessons from the experience of English and French language promotion agencies to shape a good reputation of Chinese language. We should focus on how to dispel the stereotyped understanding that "Chinese characters are pictures" and "Chinese is the most difficult language to learn in the world". We should also concentrate on promoting the international dissemination of Chinese language. By doing so, the goal of eliminating barriers, promoting culture exchange and enhancing the national cultural soft power can be achieved.

\section{B. Mutual Learning and Building a Community of Shared Future for Mankind}

The world is made up of different civilizations. And it is wonderful because of the coexistence of different civilizations. Building a community of shared future for mankind is a realistic requirement in the new era of global development. We should "transcend cultural barriers through civilization exchanges, transcend cultural conflicts through mutual learning, and transcend cultural superiority through coexistence of civilizations". We should re-examine the Chinese culture from the world multi-cultural pattern. Chinese culture is not only Chinese, but also the world's. It is part of the world's magnificent culture. And it made a major contribution to human civilization. We should respect cultural diversity, strengthen exchanges among different cultural subjects, enhance the recognition, popularity and reputation of Chinese culture in the international community, and promote the construction of a community of shared future for mankind. We believe that we can increase the share of Chinese culture in the international community. We also believe that Chinese culture will be recognized by more and more people. Chinese concept, Chinese model and Chinese value will enjoy a high reputation in the international community. Chinese culture, Chinese demeanor, Chinese wisdom and Chinese charm will also be convinced and shared by more and more people. The pleasure of foreign people in the process of aesthetic appreciation of Chinese culture will be continuously improved.

\section{CURRENT Challenges FACED By CHINESE LANGUAGE AND CUlTURE "GoING GlOBAL"}

At present, the "language strategy" and "cultural strategy" have become an integral part of the national development strategy, and the Chinese language and culture "going global" has attracted the attention of the government and all walks of life. The "Chinese fever" and "Chinese culture fever" that has arisen around the world have also brought new opportunities for Chinese language and culture to "go out". However, Chinese language and culture are still facing many challenges when "going out", which are mainly reflected in the following aspects.

\section{A. The Conflict of Mainstream Values in the West}

In today's world pattern of economic globalization and cultural pluralism, "Western centralism" still dominates the prevailing concepts and standards. In particular, some western countries promote cultural superiority and inferiority to the world as well as advocating world values, liberalism, positivism and other ideas based on their economic hegemony. It is not enough for the Chinese to excavate their excellent culture and their self-confidence is not strong enough, too. There exists the phenomenon of lack of cultural identity and worshiping everything foreign. Great contrast lies in the upsurge of learning English and the degradation of mother tongue. The pursuit of foreign festivals is also a sharp contrast to the neglect of traditional Chinese festivals. Along with the promotion of China's international status, some western countries put on the "threat theory of Chinese culture" and "cultural invasion" for the promotion of Chinese language and culture under the guise of freedom and equality. For example, Confucius Institutes have been distorted as a spy agency for cultural infiltration and cultural invasion of the Chinese people. News of the suspension of Confucius Institutes in the international community has been constantly emerging. To a certain extent, this has caused a bad effect to 
the promotion and dissemination of Chinese language and culture in the world.

\section{B. Insufficient Experience of Chinese Language and Culture "Going Global"}

Compared with other mature organizations of language and culture promotion in the world, the history of language and culture promotion in China is very short. China's language and culture promotion has not yet had mature experience in strategic positioning, communication system, and communication strategies. At present, the main institutions engaged in the promotion of Chinese language and culture in China is China National Office for Teaching Chinese as a Foreign Language (NOTCFL)/Confucius Institute and the Overseas Chinese Affairs Office of the State Council, etc. These two organizations have their own roles in the work. And there is not enough cooperation between them. This is not conducive to the macro-strategy of Chinese language and culture "going global" from the top-level design. In addition, the "Going Global Strategy" of Chinese language and culture has no mature experience in the path and strategy of language and culture transmission, which has affected the awareness of Chinese language and culture in the world. In the international community, the use of Chinese language is still very limited. And its status and discourse power are relatively low. The cultural loss caused by English translation has a direct impact on the knowledge and recognition of Chinese language and Chinese culture in the world. In a pluralistic cultural pattern, foreign people's cognition of China and Chinese culture is still one-sided. The Great Wall, giant panda, Chinese Kung Fu, dumplings and Spring Festival have become the main symbols of Chinese culture. Western society's interpretation of China is either an ideal kingdom or a symbol of poverty, backwardness, stupidity, ugliness, vulnerability and cunning.

\section{The Understanding of the "Going Global Strategy" of Chinese Language and Culture Is Still Relatively Vague}

The goal of Chinese language and culture "going global" is to enhance the influence of Chinese culture in the world, to construct a pluralistic cultural pattern and to promote the construction of a community of shared future for mankind. However, currently there is no clear understanding of what kind of Chinese culture is disseminated by Chinese language promotion agencies in China. As the most important Chinese cultural promotion institution in China, the Confucius Institute hasn't had a clear positioning on what kind of culture to disseminate (Yu Guomin \& Yang Ya, 2017). Academics still have different opinions on the "going out" of Chinese language and culture, with some emphasizing the promotion of cultural communication by language popularization (Hu Fanzhu, etc., 2017) while some emphasizing the promotion of language communication by culture popularization (Luo Feng, 2013). In the international teaching of Chinese, there still exists the tendency of emphasizing language learning while neglecting culture. The mainstream view still holds that the essence of Chinese teaching lies in the mastery of Chinese as a communicative tool. Therefore, teachers should teach little Chinese culture or even neglect it in their Chinese teaching (Lu Jianming,
2013; Li Quan \& Ding Qiuhuai, 2017). The divergence of cognition indicates the complexity of the promotion of Chinese language and culture. This urges us to reconsider Chinese language and culture "going global" as well as constructing the strategic pattern of Chinese language and culture "going global" from the top-level design as soon as possible in order to promote Chinese language and culture to the world.

\section{The Path ChOICE OF ChInese LANGUAGE AND \\ CUlture "GoING GlobaL" FROM THE PERSPECTIVE OF CulTural CONFIDENCE}

"The era is the mother of thought." The current "Going Global Strategy" of Chinese language and culture should follow the national strategy closely and make new achievements in building cultural confidence and promoting national soft power. Through the dissemination of Chinese language, we try to introduce contemporary China which is full of charm and creativeness to the world.

\section{A. Establishing Cultural Confidence and Clarifying the Positioning of Communication}

Language is both the carrier of culture and the culture itself. Maintaining self-confidence in Chinese language and culture is the psychological basis for Chinese language and culture "going global". First of all, we must have confidence in Chinese language as well as the culture carried by Chinese language. Chinese, as the communicative language of the Chinese nation for thousands of years, has precipitated the way and thinking habits of the Chinese nation in recognizing the world, and embodied the Chinese culture of behavioral communication. At the same time, Chinese language is also the most intuitive and realistic window for the world to understand China. As a tool of communication, language is also a tool of identification. Language identity is the foundation and core of cultural identity. Promoting Chinese language to the world can accelerate the world's recognition of Chinese culture. China's excellent traditional culture and contemporary Chinese culture are proved by practice. It is the culture that is in line with the Chinese people's understanding as well as thinking, and can make China move forward. With the western discourse system and values being in the mainstream, self-confidence in Chinese language and culture and self-affirmation of Chinese values are conducive to eliminating the negative impact of Western values and establishing the status of Chinese language and culture in a multi-cultural context.

Secondly, we should clarify the strategic goal of Chinese language and culture from the top level design. At present, Chinese language and culture "going global" is mainly based on overseas Chinese teaching. In the context of the new era, Chinese language and culture "Going Global Strategy" should follow the national cultural strategy and adjust its objectives and orientation in time, so as to build an international or regional common language, enhance mutual learning among civilizations and promote the construction of a community of shared future for mankind. We should break through the old cultural communication pattern of "good wine needs no bush" and break through the communication 
pattern of "disseminating what the learners need". It is necessary to do a top-level design from a strategic height, make a clear positioning and formulate the stage as well as strategy of cultural dissemination so as to promote the external dissemination of Chinese culture in an orderly manner.

\section{B. Excavating Cultural Content and Exploring Chinese Values}

General Secretary Xi Jinping (2017) pointed out that "to introduce China, we should not only introduce China with its own characteristics, but also introduce China in an all-round way; we should introduce both ancient China and contemporary China; we should also introduce China's economic and social development, as well as its people and culture." In Michael Kahn-Ackermann's opinion (2012), the goal of today's cultural exchanges is not to promote one's own culture or one's own values, but to build a stage for mutual understanding.

First of all, we must seek those with universal values in Chinese culture. Chinese civilization has a long history. The core values of Chinese culture, such as "benevolence", "harmony between man and nature", "do not impose on others what you yourself do not desire", have a wide range of influence and have been widely recognized by all countries in the world. As Chinese language and culture "going global", we should dig deep into the fine traditions of Chinese culture and highlight the "universal value" of Chinese culture. On the other hand, we should advocate the cultural concept of "mutual learning of civilizations" as well as "mutual respect and treasure other's culture and values", respect the multicultural pattern of the world, highlight the "harmony but not sameness" of Chinese culture, and avoid the tendency of cultural infiltration and cultural assimilation in cultural dissemination.

Secondly, we should explore the Chinese value of Chinese culture and show the real and comprehensive China to the world. The ideas and concepts of the Chinese culture have distinct national characteristics and time value, such as "the people are the foundation of the country", "rise and fall of a nation rests with every one of its citizens", "the mind of the superior man is conversant with righteousness", "providing assistance to needy people", "do not worry about scarcity, but rather about uneven distribution", etc. The core socialist values are rooted in these excellent historical cultures. Chinese culture emphasizes the concepts of "society of great harmony", "the world is equally shared by all" and "extensive loving all things", which are the cultural source of constructing the community of shared future for mankind. Chinese culture is both historical and contemporary. It is both national and worldwide. With Western values being the mainstream in the world cultural pattern, we should not only promote Chinese language and communication culture, humanistic culture, economic culture to the world, but also spread Chinese value culture and concept culture. As Xi Jinping (2017) said, the contemporary Chinese values should "go global", since it is the logical necessity to enhance cultural confidence and improve the country's soft power. We should attach importance to the interpretation of contemporary China, explore cultural values, build cultural brands, and show the world a true and comprehensive China.

\section{Cultivating the Main Body of Communication and Promoting Cultural Communication}

Chinese language and culture "going global" must rely on the cooperation of multiple subjects. Chinese language is the main way for Chinese culture to "go global". We should give full play to the leading role of language teaching in cultural communication, and promote Chinese language and culture to "go global" through the language teaching of international Chinese teachers, overseas Chinese associations and local Chinese teachers. We should transform the audience into the main body of communication, which can be expanded by the method of "snowball". By doing so, we constantly promote the inheritance of Chinese language and culture.

First of all, international Chinese teachers should be the leaders in the transmission of Chinese language and culture, and should tell Chinese stories well. International Chinese teachers are not only the disseminators of Chinese language and culture, but also the identity of Chinese culture. They represent the international image of China and play an exemplary role in the dissemination of Chinese language and culture. International Chinese teachers should give full play to their potential role of "public diplomacy" and "public image" in language teaching. They also have the responsibility to tell Chinese stories well and spread Chinese voice well.

Secondly, we should cultivate a number of Chinese societies that understand China well and love China, so as to make Chinese language and culture "go global" through Chinese language education. There are about 60 million Chinese language learners spreading all over the world. They are the main body of Chinese learning. On the one hand, Chinese people know China well and they love China. Besides, they understand the narrative logic of Chinese story. The inheritance and dissemination of Chinese language and culture in the world are endless. On the other hand, the overseas Chinese understand the politics, language, culture and logical thinking mode of the country they live in. They also understand the differences between the Chinese culture and the culture of the country they live in. In this sense, they can properly integrate the Chinese culture and the culture of the country they live in through the Chinese language communication. In addition, their cultural communication can shorten the psychological distance between the disseminators and the audiences.

Finally, we must do a good job in the localization of Chinese teaching and cultivate a group of local teachers who understand China well so that they can become the transmitters of Chinese culture. At present, $99 \%$ of the Chinese learners scattered around the world are overseas. The cultivation of local Chinese teachers is imminent. Local Chinese teachers, on the one hand, have a relatively high level of Chinese language proficiency. They love Chinese language and Chinese culture. And they also have a better understanding of China. On the other hand, they have their 
own experience in learning Chinese language as well as Chinese culture, and have little psychological distance from the audience. Therefore, their dissemination of Chinese culture is more vivid and easier for the audience to understand. And "cultural infiltration" can be avoided at the same time.

\section{Changing Communication Strategies and Broadening Channels of Communication}

On the basis of defining the strategic orientation and dissemination content, we should actively explore new strategies for the dissemination of Chinese language and culture. And we should also continue to broaden new channels for its dissemination.

First, we must change the communication strategy of linguistic culture. The true internal cause of most language learners around the world who are interested in Chinese language and culture is to obtain the dividends brought about by China's economic, social and cultural development. In order to spread Chinese language and culture to the outside world, it is necessary to change the concept of cultural communication. With the aim and starting point of providing appropriate services to the audience, we should disseminate different cultures to the audience and make the learners realize that learning Chinese language and culture is a linguistic investment and of great economic value. It is necessary to break through the existing mode of cultural communication, to take into account the actual needs of the audience and to disseminate modern, understandable and practical Chinese language and culture. We should pay attention to the individual and regional differences in cultural needs, and disseminate different cultures according to different individuals and regions. We should also pay attention to the stage of cultural dissemination, and spread Chinese language and culture in a phased way.

Second, we should actively broaden the channels for the dissemination of Chinese language and culture, explore new modes for the international dissemination and exchange of them, and construct an all-round, multi-level and wideranging network for the dissemination of Chinese culture by means of interpersonal communication, mass communication and electronic communication. On the one hand, we should give full play to the typical leading role of international Chinese teachers, and integrate Chinese culture into classroom teaching, cultural experience and cultural exchanges so as to effectively promote the spread of Chinese culture to the outside world. On the other hand, we should expand the platform and carrier of external communication, and use electronic communication as well as mass media to broaden the channels of communication. We should also make full use of the flexibility of the Internet, the diversity of resources, the fragmentation of learning time and the entertainment of Chinese cultural products in an attempt to develop more film and television resources as well as other cultural products, and to promote Chinese language and culture in all aspects and in a wide range of fields.

\section{CONCLUSION}

With the enhancement of its economy and comprehensive power, China is playing a more and more important role in the international arena. The international community wants to understand China and the desire to recognize China is growing stronger. More and more people want to learn Chinese language and understand Chinese culture. The worldwide "Chinese fever" and "Chinese culture fever" not only affirm the value of Chinese language and culture, but also provide infinite reverie for Chinese language and culture to "go global" with confidence. Chinese language and culture should "go global" in the way of Chinese language "going first" while Chinese culture "keeping pace". From the perspective of cultural confidence, it is necessary to actively promote Chinese language and culture in the world and strengthen the soft power of the country by excavating cultural content, cultivating cultural communication subjects, and changing communication strategies as well as methods.

\section{REFERENCES}

[1] Xi Jinpin. Excerpts from Xi Jinping's Discussion on Socialist Cultural Construction. The Central Literature Publishing House, 2017.

[2] Zhang Zhiguo. A study of Lingua Franca in the Neighboring Countries of China, Foreign Language Teaching and Research, 2016,48(02):226-235+320

[3] Yu Guoming \& Yang Ya. Chinese Discourse Communication Going Global on Key Problems - take the influence factors on the Function of Confucius Institute's Culture Dissemination as an example. International Communications, 2017(01):48-50.

[4] Hu Fanzhun \& Chen Jiaxuan \& Zhang Hongqian. Target Setting, Path Selection and Team Construction: Rethinking International Chinese Language Education in the New Era, Chinese Teaching in the World, 2018,32(01):3-11.

[5] Luo Feng. On the Nature ,System and Mode of the Globalization of Chinese Language, Chinese Language Globalization Studies, 2013(01):1-10+217.

[6] Lu Jianming. A View on the International Education of Chinese Culture Teaching, Tongji University Journal Social Science Section, 2015(02):79-84.

[7] Li Quan \& Ding Qiuhuai. The Teaching and Dissemination of Chinese Culture:Contemporary Perspective and Connotation, Applied Linguistics, 2017(01):117-124.

[8] Bruce Ackerman. Chinese Needs to Build the Basic Society's Ethics, https://news.qq.com/a/20120111/001761.htm 